Revista de la Escuela de Ciencias de la Edudcación, año 13, nRo. 12, vol. 2, JUlio a diciembre de 2017. Páginas 87-105. ISSN 1851-6297. ISSN 2362-3349 (EN LINEA). ANÁLISIS DEL TRABAJO DOCENTE: RELACIONES ENTRE LO PRESCRIPTO Y LO REAlizado en Clases de lengua y literatura. Stella Maris Tapia

\title{
ANÁLISIS DEL TRABAJO DOCENTE: RELACIONES ENTRE LO PRESCRIPTO Y LO REALIZADO EN CLASES DE LENGUA Y LITERATURA
}

\author{
Por Stella Maris Tapia* \\ Universidad Nacional de Río Negro, Argentina. \\ stapia@unrn.edu.ar
}

Recibido: 02/08/2016 Aceptado: 29/11/2016

\section{Resumen}

El análisis del trabajo docente constituye una metodología que permite una revisión del actuar de los profesores en su labor. Desde el campo de la didáctica de la Lengua y la Literatura con esta metodología que se inscribe en el marco teórico del interaccionismo socio-discursivo, se indagan en clases de Lengua y Literatura, las transposiciones didácticas en las transiciones entre los objetos de enseñanza, con sus diferentes niveles de prescripción, y su realización efectiva en objetos enseñados. La distancia entre lo planificado y lo realizado efectivamente en las clases permite diferenciar, por un lado, lo concretado de aquello abandonado en situación y, por otro lado, los emergentes, tanto si son incorporados a las clases como si son inatendidos por los docentes. Las relaciones entre las categorías sistematizadas constituirían un insumo metodológico y un instrumento didáctico que podrían facilitar el análisis de clases en diferentes instancias de investigación y formación docente.

Licenciada y Profesora en Letras (Universidad de Buenos Aires) y Doctora en Ciencias de la Educación (Universidad Nacional de Córdoba). Profesora adjunta regular del área Formación Docente, desarrolla su tarea docente en Didáctica de la Lengua y la Literatura y Prácticas de Enseñanza, en los Profesorados de Lengua y Literatura en modalidad presencial y virtual (Ciclo de Complementación) en la Universidad Nacional de Río Negro, Bariloche, Sede Andina. Co-dirige el proyecto de investigación Modelos didácticos disociados: enseñar lengua o enseñar literatura (UNRN, 40-B-362, período 2015-2018. Dir: D. Riestra). 
Palabras clave: Análisis del trabajo docente - Interaccionismo socio-discursivo - Clases de Lengua y Literatura - Trabajo planificado - Trabajo concretado.

\section{Abstract}

The analysis of teacher work is a methodology that enables a review of teacher behaviour. From the point of view of Language and Literature didactics, by this methodology - which falls within the theoretical framework of socio-discursive interactionism - we delve into the didactic transpositions in the transitions between intended learning objects, with their different levels of prescription, and the objects actually taught in Language and Literature classes. The gap between what was planned and what is actually performed in class enables us to distinguish, on the one hand, what was carried out from what was left aside in factual situations, and, on the other hand, the emergent elements, both incorporated in class or ignored by teachers. The relationships between the systematized categories are a methodological input and didactic tool that could facilitate the analysis of classes in different instances of research and teacher training.

Key words: Teacher work analysis - Socio-discursive interactionism - Language and Literature classes - Work planned - Work performed.

\section{Introducción}

El objetivo del presente artículo es sistematizar diferentes categorías construidas en relación con el análisis del trabajo docente desde el marco teórico del interaccionismo socio-discursivo (Bronckart, 2007; Riestra, 2010a). Estas categorías ordenadas constituyen un instrumento metodológico que posibilitará el análisis de 30 clases de Lengua y Literatura en el proyecto de investigación "Modelos didácticos disociados: enseñar lengua o enseñar literatura" (Dir: D. Riestra), actualmente en ejecución en la Universidad Nacional de Río Negro, Bariloche, Argentina.

La necesidad de poner en relación los diferentes niveles de planificación de las clases y lo que efectivamente sucede en ellas, en la interacción entre docentes y alumnos, se enmarca en la investigación en didáctica de la Lengua y la Literatura, disciplina de intervención que procura explicar el trabajo docente con la pretensión de transformarlo. Así, el interés por ahondar en el trabajo docente radica en la posibilidad de que los profesores reflexionen acerca de las situaciones que se presentan en la realización de la tarea, los recursos con los que cuentan y los obstáculos que hallan en su actuar cotidiano, para propiciar su desarrollo profesional a través de la concienciación de la actividad realizada.

Bronckart (2007) propone un método de análisis del trabajo docente basado en los desarrollos teórico-prácticos provenientes de la ergonomía; el 
Revista de la Escuela de Ciencias de la Edudcación, año 13, nRo. 12, vol. 2, JUlio a diciembre de 2017. Páginas 87-105. ISSN 1851-6297. ISSN 2362-3349 (EN LINEA). ANÁLISIS DEL TRABAJO DOCENTE: RELACIONES ENTRE LO PRESCRIPTO Y LO REAlizado en Clases de lengua y literatura. Stella Maris Tapia

análisis incluye los dispositivos disponibles que pueden transformarse en la acción concretamente. Identifica tres componentes del análisis: el trabajo real, el trabajo prescripto y el trabajo representado.

El trabajo prescripto es una categoría que designa los documentos donde se indica deónticamente el actuar, contemplando diversos niveles. Un primer nivel lo constituyen los documentos oficiales. En un segundo nivel, ubicamos los documentos auto-prescriptos generales (Tapia y Riestra, 2014), cuyo diseño implica la progresión de contenidos y actividades, en un período de tiempo prolongado, usualmente en el transcurso del año escolar.

El trabajo real es, según Bronckart, lo que sucede efectivamente como tarea del docente - trabajador en una situación concreta. Es la práctica en un contexto histórico y situado (Riestra, 2010a), cuyo espacio físico inmediato es el del aula, y con un tiempo circunscripto: el tiempo de la clase (Souto, 1996). El análisis del trabajo real nos permite ver que lo prescripto y lo planificado no es coincidente con lo realizado, ya que los trabajadores no siguen linealmente los procedimientos, sino que los reinventan al enfrentarse con las circunstancias situadas en las que se desarrolla su actuar (Yvon y Clot, 2004; Bronckart, 2007; Riestra, 2010a; Tapia y Riestra, 2014; Goicoechea, 2015).

Por su parte, el trabajo representado implica las dimensiones del trabajo interpretado por los actantes, por lo que, como señala Riestra (2010a), abarca el conjunto de representaciones colectivas que movilizan el trabajo docente (como cualquier otro trabajo humano) que, en muchos casos, operan como representaciones sociales inconscientes. El trabajo representado supone una interpretación anterior y luego, una reinterpretación posterior a la tarea en la que se confronta a los trabajadores con la observación de su comportamiento ( $v g$. en la investigación, con la transcripción textual de una clase observada - registro etnográfico). El objetivo de la auto-confrontación del docente con lo realizado en las clases es generar una instancia de reflexión en el trabajador a partir de la toma de conciencia de los motivos de las decisiones asumidas y de las finalidades de su operar. El abordaje de este aspecto, por razones de extensión, será dejado de lado en el presente artículo.

Las categorías precedentes de análisis de trabajo docente son discriminadas para enfocar diferentes modos en los que transcurren las transposiciones didácticas en clases de Lengua y Literatura. En primer lugar, se consideran los alcances de los documentos prescriptos del trabajo docente; en segundo lugar, se sintetizan categorías usadas en anteriores proyectos de investigación (Riestra, 2004 y 2008) para analizar las clases de Lengua y Literatura; en tercer lugar, se presenta un gráfico para esquematizar las relaciones posibles entre el trabajo auto-prescripto y las dimensiones del trabajo real, para finalizar, a modo de ejemplo, dando cuenta del funcionamiento de las categorías en el análisis de dos clases de Lengua y Literatura de nivel secundario. 
Revista de la Escuela de Ciencias de la Educación, año 13, nRo. 12, vol. 2, julio a diciembre de 2017. PÁginas 87-105. ISSN 1851-6297. ISSN 2362-3349 (EN LINEA). ANÁLISIS DEL TRABAJO DOCENTE: RELACIONES ENTRE LO PRESCRIPTO Y LO REAlizAdo En Clases de lengua y literatura. Stella Maris TAPia

\section{Los distintos niveles de prescripción del trabajo docente}

Las prescripciones, en líneas generales, son documentos que procuran señalar lo que el trabajo debe ser a través del lenguaje. Se caracterizan por la anticipación y el encuadre explícito de la actividad del trabajo, con la que buscan dotarla de una secuencialidad racionalizada (Schwartz, 2002). Se materializan en textos, es decir, productos de la actividad del lenguaje. Dichos textos son pasibles de analizarse metodológicamente en relación con las actividades generales en las que se producen, en su contenido y en su arquitectura textual. Para esto último se sigue el modelo descendente propuesto por Bronckart (2004, modificado parcialmente en 2008 y 2012), que contempla la infraestructura o planificación general de la organización temática y discursiva, los mecanismos de textualización y los mecanismos de asunción de la responsabilidad enunciativa.

El análisis textual de los documentos prefigurativos (trabajo prescripto), en sus diversos niveles de concreción, tiene por finalidad, entre otros aspectos, "observar cómo es presentado el actuar prescripto, es decir, el actuar formativo a desarrollar en clase" (Bronckart, 2007, p. 179), considerando cómo se describen las fases del proceso de enseñanza y aprendizaje, sus actores responsables, sus agentes (aquellos presentados como eslabones que no ejercen influencia sobre el proceso mismo) y su grado de generalidad.

Faïta (2002), por su parte, considera que aunque el trabajo de enseñanza está sometido a muchas prescripciones diversas (nacionales, locales, científicas y didácticas), la distancia entre esa cantidad heterogénea de prescripciones de maneras de hacer y el trabajo real resulta mayor en el trabajo docente que en otras prácticas profesionales. Señala, como causas de este alejamiento, las particulares condiciones de la enseñanza: la globalidad de la prescripción frente a la variabilidad inherente a las condiciones del trabajo docente y el hecho de que las disposiciones y recomendaciones apuntan tanto a la actividad de los docentes como a la actividad de los alumnos. Agrega el autor, como otro de los factores, la "nebulosa de situaciones por crear" que implica una serie de auto-prescripciones y prescripciones para con los alumnos que da validez al mandato oficial (prescripciones para transmitir saberes y organizar el medio de trabajo de los alumnos, prescripciones para generar relaciones del grupo de la clase con el aprendizaje): "Esto refuerza notablemente lo borroso de la prescripción y ejerce sobre los enseñantes una constricción más fuerte en el sentido de elaboración de auto-prescripciones" [Trad. propia] (Faïta, 2002, p. 20). Consideramos que resulta pues, necesario, indagar en al menos dos niveles distintos de prescripción del trabajo del profesor de Lengua y Literatura: la prescripción externa y la auto-prescripción o trabajo planificado. 
Revista de la Escuela de Ciencias de la Educación, año 13, nRo. 12, vol. 2, Julio a diciembre de 2017. Páginas 87-105. ISSN 1851-6297. ISSN 2362-3349 (EN LINEA). ANÁLISIS DEL TRABAJO DOCENTE: RELACIONES ENTRE LO PRESCRIPTO Y LO REAlizado en Clases de lengua y literatura. Stella Maris Tapia

\section{1. Las prescripciones externas: los documentos oficiales, las propuestas didácticas}

Entre los documentos oficiales del Ministerio de Educación de la Nación Argentina que prefiguran el trabajo de enseñar Lengua y Literatura, se encuentran los Núcleos de Aprendizajes Prioritarios (NAP), que a nivel local o provincial deberían adaptarse, plasmarse y reajustarse en diferentes Diseños Curriculares jurisdiccionales.

La organización de los NAP para la Escuela Secundaria es por niveles, ciclos y asignaturas; corresponden al Ciclo Básico los NAP (2011) que contemplan $1^{\circ}$ y $2^{\circ}$ año de Educación Secundaria en Jurisdicciones con Nivel Primario de 7 años y $2^{\circ}$ y $3^{\circ}$ año de Educación Secundaria en Jurisdicciones con Nivel Primario de 6 años. Los NAP para el Ciclo Orientado (2012) abarcan $3^{\circ}$ año ( $4^{\circ}$ año, si la primaria es de 6 años), por una parte, y, por otra parte, $4^{\circ}$ y $5^{\circ}$ conjuntamente (o $5^{\circ}$ y $6^{\circ}$, ídem). Los NAP configuran la acción en un nivel muy general, puesto que no delimitan contenidos ni objetivos sino "aprendizajes prioritarios", definidos, en los mismos documentos, de la siguiente manera:

Un núcleo de aprendizajes prioritarios en la escuela refiere a un conjunto de saberes centrales, relevantes y significativos, que incorporados como objetos de enseñanza, contribuyan a desarrollar, construir y ampliar las posibilidades cognitivas, expresivas y sociales que los niños ponen en juego y recrean cotidianamente en su encuentro con la cultura, enriqueciendo de ese modo la experiencia personal y social en sentido amplio (2011).

Estos saberes para Lengua y Literatura se organizan en cuatro ejes en el Ciclo Básico (2011): a) "En relación con la comprensión y la producción oral", b) "En relación con la lectura y la producción escrita", c) "En relación con la literatura", d) "En relación con la reflexión sobre la lengua (sistema, norma y uso) y los textos". Dichos ejes coinciden solo parcialmente con los cuatro en los que se distribuyen los saberes en el Ciclo Orientado (2012): "Lectura y escritura de textos literarios", "Lectura y escritura de textos no literarios", "Comprensión y producción de textos orales" y "Reflexión sobre el lenguaje".

El análisis lingüístico parcial que hemos realizado de estos documentos que prescriben el trabajo del profesor de Lengua y Literatura, a partir de Bronckart (2004 y 2008), se centra en los mecanismos de cohesión verbal para ubicar las acciones referidas en los enunciados. Se han focalizado algunos verbos y los roles sintácticos atribuidos a los protagonistas del actuar formativo siguiendo una metodología ya empleada (Tapia y Goicoechea, 2012). Se revela así el uso de formas impersonales por nominalizaciones ("la participación", "la escucha", "la producción sostenida", "la lectura reflexiva", "el reconocimiento") combinadas con formas en infinitivo ("recuperar", profundizar", "explorar", "participar", "descubrir", "vincular", "indagar", "analizar", "participar", "reflexionar") en construcciones que prescinden de un agente. Esto es, lin- 
güísticamente, en los NAP no se remarca ni a alumnos ni a docentes como participantes responsables de las acciones de aprender y enseñar. El documento alude a los aprendizajes despojados de su relación con los alumnos que se suponen sujetos activos de estos aprendizajes pero a los que se borra, enunciativamente, en su carácter agentivo. En cuanto a los docentes, cuando son mencionados, aparecen en construcciones que funcionan gramaticalmente como adjuntos, con rasgos semánticos de compañía o instrumento. Son formas que se repiten: "reflexión sistemática, con ayuda del docente, sobre distintas unidades", "con la mediación del docente", "con la colaboración del docente", "mediante la interacción con el docente y los pares", "con apoyo del docente", etc. Únicamente en la relación con la oralidad, los textos de los NAP (2011 y 2012) ubican a los docentes en una función agentiva, cuando señalan que la participación de los alumnos se realizará en "debates moderados por el docente".

En cuanto al análisis de los mecanismos de enunciación, resulta significativa la omisión, en un documento de carácter netamente prescriptivo, de modalizaciones deónticas, es decir, aquellas que evalúan el contenido temático en relación con los valores y las reglas del mundo social (Bronckart, 2004, p. 200). Estas cuestiones discursivo-textuales pueden considerarse indicadores de las concepciones sobre enseñanza, aprendizaje y sobre el rol otorgado a los docentes que subyacen en los NAP.

En otro orden, los Diseños Curriculares constituyen documentos destinados a prescribir contenidos y dar indicaciones acerca de los procesos de enseñanza y aprendizaje de cada una de las asignaturas en las diferentes jurisdicciones (Provincias y CABA) y en los distintos niveles de educación. Desde la sanción de la Ley de Educación Nacional (Ley 26.206) en 2006, y de acuerdo con los "Lineamientos políticos y estratégicos de la Educación Secundaria Obligatoria" (Consejo Federal de Educación, Resolución 84/09, octubre de 2009) las jurisdicciones han elaborado sus Diseños Curriculares (o se encuentran en proceso de elaboración, como sucede en la Provincia de Río Negro, que prevé instrumentar su nuevo Diseño Curricular para la Escuela Secundaria en 2017). Integran de manera resignificada los NAP y adecuan los objetivos determinados para Lengua y Literatura: "como espacio curricular específico a lo largo de toda la escolaridad con el propósito de desarrollar saberes reflexivos acerca del lenguaje, que redunden en beneficio de prácticas de lectura y escritura, amplíen el universo cultural de los jóvenes y contribuyan al desarrollo de su propia subjetividad" (CFE, 2009).

Las propuestas didácticas y los manuales configuran otros modelos que pueden ser apropiados por los profesores para su actuar docente y en este sentido constituyen prescripciones de su actuar. Estos modelos llegan, para las asignaturas Lengua y Literatura y afines, muchas veces como aplicacionismos de las ciencias del lenguaje (o "bajadas al aula" de conocimientos propios 
Revista de la Escuela de Ciencias de la Educación, año 13, nRo. 12, vol. 2, Julio a diciembre de 2017. Páginas 87-105. ISSN 1851-6297. ISSN 2362-3349 (EN LINEA). ANÁLISIS DEL TRABAJO DOCENTE: RELACIONES ENTRE LO PRESCRIPTO Y LO Realizado en Clases de lengua y literatura. Stella Maris Tapia

del campo de la Lingüística, con escasa o nula transposición), conforman modelos teóricos descriptivos y explicativos, que sirven para clasificar o etiquetar hechos del lenguaje y como afirma Riestra (2010b) se articulan con modelos sociales:

Tomados en préstamos de las ciencias del lenguaje, a veces muy influenciadas por modelos de las ciencias exactas; nos llegan aplicaciones de modelos hipotéticos como si fueran verdades indiscutibles que entran a las aulas casi inadvertidamente, sin análisis previo, por la divulgación científica, en general, surgida de las políticas editoriales. [...] en las últimas décadas del siglo XX se instalaron unos modelos hipotéticos como prescripciones en los textos (orales y escritos) de la formación docente y alcanzaron hasta los manuales escolares (2010b, p. 3).

Documentos oficiales de distinto alcance jurisdiccional, propuestas didácticas, manuales escolares, constituyen diferentes modos en los que se construye externamente qué y cómo debería enseñar un profesor de Lengua y Literatura. El entramado de estos niveles de prescripción conlleva diversas apropiaciones y modos de concebir y pre-configurar el trabajo del docente en el área. Podemos preguntamos qué valor tienen para los profesores estas prescripciones y cómo las resignifican, si se las apropian (y en qué grado), si las reelaboran, si las evalúan, si conforman síntesis coherentes en el trabajo auto-prescripto o si, por el contrario, se suman de manera desarticulada, desconociendo lo incompatible, lo contradictorio, lo incoherente, entre diferentes concepciones epistemológicas sobre los objetos de enseñanza que subyacen, a la manera de las capas de un palimpsesto, en las transposiciones didácticas operadas por los sucesivos niveles de plasmación de las prescripciones externas.

\section{2. El trabajo auto-prescripto o planificado}

Los programas y las planificaciones anuales de los docentes se erigen como textos intermedios entre los documentos oficiales y lo auto-prescripto, puesto que, en muchos casos, son las instituciones escolares las que determinan y delimitan un modelo de programa y de planificación con elementos prestablecidos (cuadros, esquemas, plantillas, etc.) a completar por los profesores. Estos elementos pueden condicionar la forma en que son concebidos los instrumentos, no obstante, hay, en la planificación, una auto-prescripción de lo que el trabajo debe ser. Esa auto-prescripción cobrará dimensiones diferentes si es apenas esbozada en una planificación anual o si se trata de una secuencia que alcanza los niveles de la consigna de cada clase. En este último caso, puede analizarse la repetición, la reformulación o las transformaciones operadas entre las consignas como instrumentos planificados y la consigna efectivamente dada en clase como guía de lo realizado (Riestra, 2004). 
Con respecto a la distinción entre planificación y secuencia, en el marco del proyecto "Modelos didácticos disociados: enseñar lengua o enseñar literatura" se han recolectado y se están analizando los textos auto-prescriptos elaborados por docentes de nivel primario y secundario, correspondientes a 30 clases agrupadas en lo que los docentes califican como secuencias. Se disntinguen, en los textos de planificaciones y secuencias, además de los objetos de enseñanza y el modo en que es concebida la transposición didáctica en el área, las variadas formas de concebir prefigurativamente el propio trabajo, la diversidad en el grado de planificación previo de cada tarea y cierto margen de alternancia entre creatividad y repetitividad o estandarización en la formulación del trabajo auto-prescripto, en el que consideramos necesario continuar indagando.

\section{La relación entre el trabajo prescripto y el trabajo real en el análisis de clases}

Las clases observadas y transcriptas con un registro etnográfico son textos que muestran lo efectivamente realizado en el aula. Dan cuenta del diálogo en la interacción entre docentes y alumnos. Lo transcripto como texto es considerado el trabajo real y resulta, como tal, un objeto de análisis a confrontar con el trabajo prescripto en sus distintas etapas de plasmación.

El primer nivel de análisis del trabajo real es el de la consigna que organiza la clase, mientras que el segundo nivel surge de considerar el diálogo de la clase y los emergentes didácticos, como un conjunto de sucesos y de enunciados en torno a los objetos de enseñanza, las transposiciones didácticas y los procesos de enseñanza y aprendizaje que no han sido planificados, sino que transcurren durante la interacción docente-alumnos.

La consigna, en el primer nivel de análisis, constituye un documento prescriptivo para guiar las actividades de los alumnos. Es un instrumento que aporta a la planificación de la enseñanza (Riestra, 2008). Consideramos a la consigna, metodológicamente, como "el dispositivo concreto utilizado en las distintas clases para abordar las intervenciones didácticas en los procesos de interacción con los alumnos" (Riestra, 2008, p. 237). Se trata, según la autora, de un saber enunciar para problematizar a los sujetos que aprenden: formular enunciados con intencionalidad, que procuran influir en las acciones y operaciones mentales de los alumnos para producir determinadas apropiaciones de contenidos. Asimismo es "un proceso psicológico a ser construido por los enseñantes para ser realizado por los alumnos, por lo que puede considerarse como instrumento desde la perspectiva didáctica: lo planificado, prefigurado y analizado sistemáticamente" (Riestra, 2008, p. 311).

En las clases como textos se reconocen las consignas en sentido estricto, identificando sus sucesivas reformulaciones, y diferenciando, además, un conjunto de tareas prescriptas (lo que el docente solicita a los alumnos que 
Revista de la Escuela de Ciencias de la Educación, año 13, nRo. 12, vol. 2, Julio a diciembre de 2017. Páginas 87-105. ISSN 1851-6297. ISSN 2362-3349 (EN LINEA). ANÁLISIS DEL TRABAJO DOCENTE: RELACIONES ENTRE LO PRESCRIPTO Y LO REAlizado en Clases de lengua y literatura. Stella Maris Tapia

hagan concretamente), nociones teóricas y nociones didácticas (transposiciones) con respecto a los contenidos de enseñanza. La reformulación de la consigna guía la clase y (re)dirige las acciones que el docente ha planificado para que los alumnos realicen.

La confrontación entre lo planificado y lo realizado en el registro de las clases (segundo nivel de análisis) permite diferenciar lo concretado de lo que resulta abandonado. Se entiende "lo concretado" como aquello de la planificación que se realiza efectivamente y se agrega así un cuarto elemento al análisis del trabajo docente desde el interaccionismo socio-discursivo, no contemplado en la síntesis elaborada por Goicoechea (2015) que integra solo tres factores: "lo abandonado", lo "inatendido" y lo "aportado en situación". Lo "concretado" permite identificar las zonas de la clase donde los objetos de enseñanza y las tareas realizadas por los alumnos concuerdan con lo que el docente prescribió que iba a realizar. Concierne a la zona de confluencia entre lo que el docente planificó que haría y lo que, en un momento posterior de auto-confrontación con la clase real, en una entrevista, puede señalar como los objetivos alcanzados de su proyecto de enseñanza.

Lo "abandonado", por su parte, remite a los contenidos y procedimientos planificados que se dejan de lado por distintos factores u obstáculos (Bronckart, 2007). Lo "inatendido" y lo "aportado en situación", pueden ser clasificados, en cambio, como emergentes didácticos.

\section{1. Los emergentes}

La definición de emergente apunta al suceso incidental, imprevisto (en el sentido de no planificado) y circunstancialmente situado en la clase. Según Pichón Riviere (1985), el emergente es una situación significativa que desde lo explícito remite como signo a formas implícitas. Por emergente didáctico entendemos un factor que resulta enunciado en los textos de las clases, que hace referencia a los objetos de enseñanza, la transposición didáctica y/o los procesos de enseñanza y aprendizaje y que puede llevar a la modificación de lo planificado. Implica la abstracción de emergentes relacionados con cuestiones institucionales, historia del grupo escolar, condiciones temporales y espaciales, aspectos vinculares o afectivos, entre otros, que se observan en las interacciones de las clases pero que no son didácticos en un sentido estricto, aunque condicionan la tarea docente. Con esta abstracción se apunta a continuar la restricción metodológica esbozada por Schneuwly (2000), centrándonos en la construcción colectiva del objeto de enseñanza, no para negar los factores involucrados que dan cuenta de la complejidad de la clase y de los procesos de enseñanza y aprendizaje, sino para delimitar el campo disciplinar y avanzar en la comprensión de cuáles son los instrumentos específicos del trabajo docente.

El emergente atendido puede definirse como lo aportado en situación o las acciones no planificadas que surgen en la interacción y que el trabajador re- 
suelve incorporar a la actividad (Bronckart el al. 2001, en Goicoechea, 2015). El emergente inatendido, en cambio, corresponde a situaciones no previstas y tampoco incorporadas a la tarea.

\section{2. Un esquema de las relaciones}

En el gráfico 1 puede verse la representación en los ejes cartesianos, entre, por una parte, lo planificado y aquello que surge en el momento de la clase o el emergente y, por otra parte, lo realizado y lo no realizado. El cruce entre el eje vertical (de lo planificado a lo no planificado) y el eje horizontal (de lo realizado a lo no realizado) nos permite ubicar las cuatro categorías hasta aquí señaladas: lo concretado es lo planificado y realizado en la clase, de allí que simbólicamente lo ubiquemos en el cuadrante que representa lo positivo (+planificado, +realizado, sin que ello implique un juicio de valor). Lo abandonado es lo planificado pero no realizado (+planificado, -realizado); el emergente atendido es lo aportado en situación, aquello que aunque el docente no ha planificado como acción, surge en la interacción de la clase y se incorpora en la tarea (-planificado, +realizado); por último, el emergente inatendido se ubica en el cuadrante de lo no planificado y lo no realizado (-planificado, -realizado).

\section{Gráfico 1}

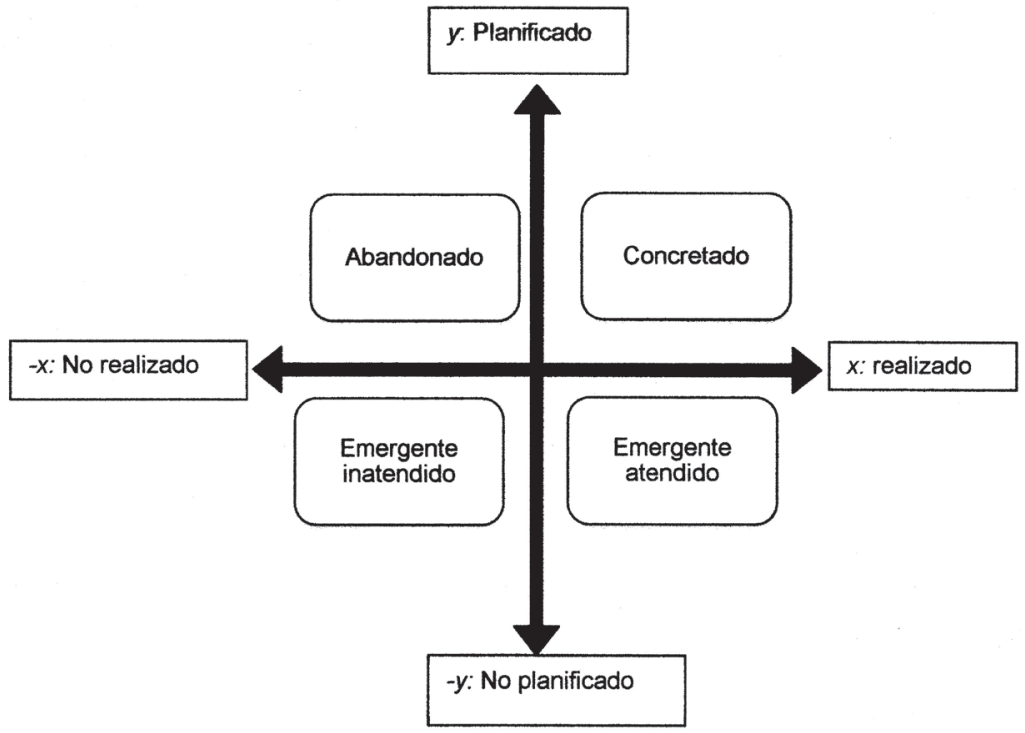

Esquema de las relaciones entre lo concretado, lo abandonado y los emergentes. 
Revista de la Escuela de Ciencias de la Educación, año 13, nRo. 12, vol. 2, Julio a diciembre de 2017. Páginas 87-105. ISSN 1851-6297. ISSN 2362-3349 (EN LINEA). ANÁLISIS DEL TRABAJO DOCENTE: RELACIONES ENTRE LO PRESCRIPTO Y LO REAlizado en CLASES de lengua y literatura. Stella Maris TAPIA

El esquema precedente permite ordenar cuatro categorías; su utilidad radicaría en que los cuadrantes definen la relación entre lo planificado y lo realizado sin olvidar que, aunque el actuar docente no coincide completamente con lo planificado, hay una zona de convergencia en la clase entre aquello que se planeó hacer y lo efectivamente realizado, a la que nombramos como "lo concretado", no ubicado hasta ahora en el análisis metodológico del trabajo docente por parte del interaccionismo socio-discursivo. La categoría trabajo concretado reviste cierto interés para revisar las prácticas docentes de modo reflexivo, particularmente durante la formación docente inicial en la etapa profesionalizante o de residencia (Tapia, 2016), ya que sería complementaria de un dispositivo didáctico para reflexionar en torno al propio actuar, a partir de una secuencia didáctica planificada, identificando los procesos de transformación de esa secuencia conforme al contexto situado y al desarrollo concreto de las clases.

La disposición espacial en el gráfico distingue una cuádruple diferenciación para el análisis de las 30 clases que conforman el corpus del proyecto de investigación, aunque por razones de extensión solo se dará cuenta, en el siguiente apartado, de cómo funciona este modelo para dos de ellas.

\section{Análisis de un documento auto-prescripto (planificación) y de dos clases de nivel secundario}

La planificación y las dos clases observadas que describiremos a continuación, con el objeto de ejemplificar lo expuesto hasta aquí, integran el corpus de clases, con sus respectivos documentos auto-prescriptos, recolectado en el proyecto "Modelos didácticos disociados: enseñar lengua o enseñar literatura". Corresponden a $5^{\circ}$ año de una escuela secundaria pública (CEM) de la ciudad de San Carlos de Bariloche y fueron observadas los días 15 y 16 de septiembre de 2015. En la Provincia de Río Negro, debido un proceso de Transformación de la escuela secundaria iniciado en 2008, que quedó sin efecto de continuidad, no hay un Diseño Curricular vigente actualizado conforme a los NAPs que se corresponda al ciclo superior de la escuela secundaria. Por ello, para el análisis de estas dos clases de $5^{\circ}$ año de la asignatura Literatura, arte y sociedad, limitaremos el análisis del trabajo prescripto al nivel del trabajo auto-prescripto o planificado por la docente.

El documento escrito por la profesora se trata de una planificación anual que enuncia propósitos generales, contenidos agrupados por trimestre con una selección de autores argentinos y latinoamericanos y sus respectivas obras literarias, tres apartados titulados "Textos e ideas complementarios", "Taller literario", "Taller de cine argentino" (incluye una lista de películas), una aclaración acerca de las características por las cuales no se propone una secuencia de actividades en la planificación, y, por último, indicaciones generales sobre la evaluación. En una auto-referencia, el texto usa, para men- 
cionarse, la forma "Planificación-Programa". En el apartado "Taller literario" se indica que los alumnos participarán en "actividades de producción literaria basadas en las técnicas propias de las dinámicas del taller de escritura". Allí mismo se consigna que estas actividades apuntarán al "desarrollo de una escritura expresiva pero solvente en la normativa y al mejor conocimiento de la literatura en tanto el alumno pase de un rol receptor a otro productor". El taller literario se presenta en su realización mediante los términos "actividades", "tareas", "ejercicios", "ejercitación" sin que se identifique distinción, por lo que podría inferirse que todos los anteriores son tratados como sinónimos en el documento. En relación con el apartado "Secuencia de actividades", se indica la imposibilidad de organizar una secuencia, circunstancia que se atribuye al taller:

No se proporciona en este Programa-Planificación [una secuencia de actividades] en tanto no se puede fijar una progresión que vaya a ser fehaciente [...] La consideración que se realiza se basa en la imposibilidad de prever cómo será la evolución del grupo de trabajo. Las tareas de taller literario, en este sentido, serán la piedra de toque para la motivación y/o remotivación del grupo.

Entre los contenidos del segundo trimestre, momento que se corresponde con la época en la que se realizaron las observaciones de clases, se enuncia: "Lectura, análisis, interpretación personal y ejercitación literaria a partir de los siguientes autores y textos [...] Cortázar, Julio: Casa tomada".

Las dos clases observadas y transcriptas como textos para su análisis, de las que nos ocuparemos a continuación, comprenden una actividad de lectura y una actividad de escritura, respectivamente, en torno al cuento "Casa tomada". El análisis de las consignas (Riestra, 2004 y 2008) permite identificar las tareas de leer el cuento y escribir, respectivamente. La consigna en sentido estricto de la clase 1 es: "Nosotros vamos a leer juntos un cuento, un primer cuento que es "Casa tomada", que es un cuento que aparece en su primer libro de cuentos que es Bestiario". En la clase 2, la consigna en sentido estricto es escrita por la profesora en el pizarrón: "Actividad de escritura: ¿Qué hacen los hermanos cuando salen de la casa?/ La historia desde los otros/ La mirada de la hermana/ Desde la casa". Esta última consigna es reformulada de la siguiente manera, en el diálogo con un alumno:

Ao5: ... ¿Qué hay que escribir?

D: Esto. Una producción ficcional. De lo que se trata es de reflexionar, esto de acá (señalando en la hoja de la alumna), cuando vos tenés una idea propia, vale, o alguna de estas también.

Ao 5: Pero tiene que ser así, como en vez de, en vez de, un relato. Pero ¿tiene que ser un relato parecido? [...] 
Revista de la Escuela de Ciencias de la Edudcación, año 13, nRo. 12, vol. 2, JUlio a diciembre de 2017. Páginas 87-105. ISSN 1851-6297. ISSN 2362-3349 (EN LINEA). ANÁLISIS DEL TRABAJO DOCENTE: RELACIONES ENTRE LO PRESCRIPTO Y LO REALIzAdo EN CLASES DE LENGUA Y literatura. Stella Maris TAPIA

Las nociones teóricas que se mencionan en las clases coinciden con los contenidos señalados en el documento auto-prescripto del Programa-Planificación: "escritura de culto" y "literatura consagrada". Se presentan estos dos conceptos, en primer lugar, como una dicotomía en la Literatura Argentina, contrastando a un escritor como Pinedo con otro como Cortázar (clase 1), para reflexionar luego, didácticamente, que los autores consagrados no son tales en sus orígenes. La noción didáctica que se transmite es formulada por la docente de la siguiente manera: “... [nos interesa estudiar] cómo se llega a esto de ser escritor". Subyace, a estas nociones, una concepción del objeto de enseñanza literatura como sistema de consolidación de determinados autores y parece connotarse un cierto prestigio o valor de la literatura considerada "de culto", definida por el acceso restringido a un público lector "iniciado". Podría notarse en ello una contradicción entre la propuesta del taller literario que se expone en el trabajo planificado (motivando a los alumnos para que todos sean escritores de sus propios textos) y lo que en las clases se desarrolla como una visión canónica de la Literatura: espacio de consagración de determinados autores mediante un sistema de reconocimiento selectivo.

La clase 1 comienza quince minutos más tarde por factores institucionales (organización de actividades del centro de enseñanza relacionadas con el día del Estudiante); esto motiva que la docente exprese, al empezar, que el trabajo planificado se verá modificado para ajustarse a los tiempos de la clase, interrumpida por un recreo: "...vamos a leer después del recreo porque ahora va a quedar inconcluso [el cuento]". Pospone el tiempo de la lectura para desarrollarla en forma completa e, insiste: "Lo único que vamos a poder hacer ahora con este pequeño corte es arrancar con el tema". La docente sitúa comunicativamente la obra literaria y la biografía de su autor. El trabajo concretado en esta clase es una contextualización de la obra "Casa tomada", la lectura en voz alta del cuento por parte de cuatro alumnas y un intercambio dialógico sobre los sentidos que se le otorgan. Después de la lectura, se sucede un diálogo sobre las interpretaciones posibles del cuento; la profesora expone, brevemente, una lectura canónica del cuento, ubicado en el momento histórico del peronismo, y el rechazo ideológico de Cortázar hacia ese movimiento, en los años 1945-1955:

D: Hubo una lectura muy difundida de este cuento, yo creo que hay que tomarla con pinzas, pero que tuvo que ver con el momento, que es una lectura política que tiene que ver con el peronismo.

Aa3: ¿Qué? ¿Por qué vienen a tomar? ¿La actitud?

D: Son los monstruos, ¿no? Son los monstruos, los cabecitas negras, la ciudad de Buenos Aires se ve invadida por estos otros, claro, esto que hablábamos del alto y el bajo, esta es una lectura. Cortázar cuenta que este cuento es un sueño que tuvo él, donde el protagonista era él, y lo que él dice, que es interesante, es que muchos de sus cuentos de Bestiario tienen 
que ver con sus propias neurosis, con su propia locura, que él dice "yo los escribía y ahora que se haga cargo el lector". Estas son cosas que dice Cortázar, que tampoco hay que tomarlo como que hay que leer lo que dice Cortázar. Cada uno de ustedes lee como tiene ganas...

La última frase condensa una concepción de la lectura que se repite en varias oportunidades en las dos clases y que coincide con la que subyace en la planificación, en relación con la interpretación personal de las obras literarias. Podría asociarse, además, con la característica atribuida a la literatura de poseer múltiples sentidos y en función de ello, como señala Cuesta (2011), a las prescripciones tanto en los NAP como en los diversos Diseños Curriculares de que la enseñanza de la literatura debe ahondar en esos múltiples sentidos e interpretaciones atribuidos por los alumnos a las obras.

En los últimos quince minutos de la clase 1, la docente relee fragmentos del cuento y vuelve sobre el sentido, marcando un pronombre personal y referencias temporales y espaciales que le permiten dar cuenta de cómo la interpretación del texto literario debería anclarse en algunos elementos textuales-discursivos.

El primer emergente que se reconoce en esta clase, momentos antes de comenzar con la contextualización, se presenta en relación con el cuestionamiento por parte de los alumnos hacia el autor. Manifiestan su disgusto y rechazo ante la lectura de obras de Cortázar, basados en las lecturas realizadas en años anteriores de la escuela secundaria. Como emergente incorporado a la clase, la docente reflexiona sobre la importancia de Cortázar en la Literatura Argentina y sostiene:

Hay una cuestión generacional, obviamente. Para mí es muy importante en mi vida. Y quiero tratar de transmitirles algo de eso a ustedes. Nosotros, la propuesta de trabajo de hoy era leer un cuento, que está en el programa, que yo lo había pensado con X... [el otro docente que firma la planificación] para poder trabajar algunas cosas[...] Poder pensar, esto pensamos con $\mathrm{X}$... cuando lo pusimos en la planificación, que es un cuento que le va a permitir a ustedes producir textos propios.

La falta de motivación de los alumnos para leer el cuento resulta un emergente. Razonar con ellos para que aborden la lectura insume mucho tiempo de la clase e implica argumentos de la profesora para justificar tanto la planificación como su propuesta metodológica:

... cuando arrancamos la cursada, habíamos hablado de que la literatura les podía permitir a ustedes construir su subjetividad, que cada uno de ustedes iba a tener una lectura, siempre que se atuviera al texto, si no era un delirio, que íbamos a respetar las lecturas y que íbamos a construir juntos. 
Revista de la Escuela de Ciencias de la Educación, año 13, nRo. 12, vol. 2, Julio a diciembre de 2017. Páginas 87-105. ISSN 1851-6297. ISSN 2362-3349 (EN LINEA). ANÁLISIS DEL TRABAJO DOCENTE: RELACIONES ENTRE LO PRESCRIPTO Y LO REALIzAdo EN CLASES DE LENGUA Y Literatura. Stella Maris TAPIA

Esta parte de la clase se sostiene en el diálogo, la docente desarrolla motivos para convencer a los alumnos de leer el cuento, mientras que ellos presentan sus objeciones debidas a experiencias previas de lecturas de Cortázar, asociadas a la obligación y a la falta de comprensión de las obras, que evalúan negativamente.

Un emergente, en esta clase, resulta inatendido; pero se incorpora en la clase 2 (16 de septiembre): el planteo de los alumnos acerca de la necesidad de abordar la conmemoración de la Noche de los Lápices, y de incorporar una reflexión compartida sobre los estudiantes secundarios desaparecidos en 1976.

Por otra parte, al iniciar la clase 1, la docente señala que ha llevado libros y que los dejará sobre la mesa para que los alumnos indaguen en las obras de Cortázar: "traje libros para que vean". Reconocemos en ello al trabajo abandonado porque, aunque la docente insiste en otros momentos para que los alumnos se acerquen a los libros, esto no sucede. Aunque no profundizaremos en este aspecto, cabe señalar que en la entrevista realizada a posteriori de las observaciones de clases con la profesora, ella evoca la presencia de los libros sobre la mesa como una distancia entre lo previsto y lo que efectivamente sucedió:

...me parece interesante en el registro de la clase esta cosa de que los libros quedaron ahí, y que quedaron como una vidriera. No hubo posibilidad de intercambio de los libros que yo llevé para que ellos miraran, entonces, en esto, yo tenía planificado, llevar, que miraran, bueno, que se pudiera intercambiar, tocar, esas cosas que me pasan a mí con los libros, si no los leen en un PDF o compran copias, entonces, me pareció que quedó todo como inconcluso.

El carácter de lo "inconcluso", lo que "queda ahí", como se manifiesta en las palabras de la docente al leer los registros de sus clases durante la entrevista, remite a lo abandonado o dejado de lado.

La clase 2 se organiza en torno a una actividad de escritura guiada por la consigna en sentido estricto ("Actividad de escritura: ¿Qué hacen los hermanos cuando salen de la casa?/ La historia desde los otros/ La mirada de la hermana/ Desde la casa"), reformulada oralmente:

Hoy, actividad de escritura, ¿recuerdan? Como ustedes saben, el que tiene ganas, porque tiene idea, arranca. Yo pensé algunas propuestas. Por ejemplo: ¿Qué hacen los hermanos cuando salen de la casa? [...] La historia desde los otros (mientras, lo escribe en el pizarrón y coloca los libros de Cortázar sobre el escritorio), si pensamos que hay otros, porque ayer algunos hablaron de unos otros, eh. Si alguno tiene ganas de hacer un trabajo escrito, eh, matando a Cortázar, tiene la posibilidad. 
Aa: Bueno, no, pero, ¿cómo matar a Cortázar?

$\mathrm{D}$ : Si alguien tiene ganas, porque tiene el argumento, se le puede ocurrir.

Ustedes saben si hacen esa lectura, vale, ¿eh?

El trabajo concretado en esta clase con respecto a la planificación es el abordaje de una reescritura desde el marco de un taller literario. Los textos escritos por los alumnos no se entregan al final de la clase; a una alumna que pregunta si la docente se llevará la producción, esta le contesta: "No, quédense ustedes con el trabajo y después me los llevo yo para corregir". Los textos no son leídos ni socializados, la clase concluye con ruido general a medida que se acerca el horario del toque de timbre y una despedida. No se marca un momento de cierre o conclusión de la actividad de escritura.

El emergente inatendido en la clase 1, el tema de la Noche de los Lápices, es reiterado como preocupación de los alumnos. La docente esta vez aborda la situación y lo incorpora a su clase, en medio de la actividad planificada, presentando la propuesta de realizar la lectura de una entrevista a una de las sobrevivientes. Esta propuesta queda planteada como cuestión a planificar para clases subsiguientes.

En cuanto al trabajo abandonado, atendiendo que la coyuntura institucional provocó que la suplencia de la docente frente al curso concluyera la semana siguiente, en algún sentido podría verse esta categoría en relación con la secuencia, porque quedó sujeto a la decisión de otro profesor si se continuaba o quedaba inconcluso lo planificado para el año escolar.

El análisis precedente nos permite señalar que el trabajo auto-prescripto se actualiza en cada concatenación de una clase a otra se analizan las continuidades y los motivos en una secuencia y pueden considerarse las capacidades del docente para conducir, planificar, revisar y ajustar lo prescripto, operando las transposiciones didácticas de los objetos de enseñanza a objetos enseñados. Podemos calificar el alcance del trabajo docente como negociación entre lo prescripto y los emergentes, apelando a la imagen que utiliza Bronckart, de pilotear una situación, en los sentidos de navegar, conducir, dirigir, gobernar, guiar:

El profesionalismo de un docente lo constituye la capacidad de "pilotear" un proyecto de enseñanza predeterminado, negociando permanentemente las reacciones, los intereses y las motivaciones de los alumnos, manteniendo la dirección o modificándola en función de criterios de apreciación que sólo él domina y de los que él es el único responsable, es decir, en el marco de las acciones donde él es el único actor. Desde una óptica más general, su profesionalismo reside en la capacidad de conducir su proyecto didáctico teniendo en cuenta múltiples aspectos (sociológicos, materiales, afectivos, "disciplinarios") a menudo subestimados y que, sin embargo, son lo "real" más concreto de la vida de una clase (2007, p. 185). 
Revista de la Escuela de Ciencias de la Edudcación, año 13, nRo. 12, vol. 2, JUlio a diciembre de 2017. Páginas 87-105. ISSN 1851-6297. ISSN 2362-3349 (EN LINEA). ANÁLISIS DEL TRABAJO DOCENTE: RELACIONES ENTRE LO PRESCRIPTO Y LO REAlizado en CLASES de lengua y literatura. Stella Maris TAPIA

En otras palabras, el profesionalismo del docente permite la toma de decisiones que justifican la continuidad y concreción de un trabajo planificado, su abandono, o su readecuación y revisión en función de los emergentes de una situación didáctica.

Aquello que se concretó, aquello que un docente incorporó en sus clases y lo abandonado, en las intersecciones entre lo planificado y lo no planificado, son indicaciones de diversas maneras en las que acontecen las transposiciones didácticas en las aulas.

Si el trabajo real coincidiera en su totalidad con el trabajo prescripto, en la zona asignada como trabajo concretado -como los docentes nóveles, en su etapa de práctica y residencia parecen desear, y como se desprendería de una primera lectura ingenua de los documentos oficiales que prescriben la labor docente (lo que el profesor debe hacer para que los alumnos aprendan)-, estaríamos en presencia de profesores autómatas, incapaces de reconocer y reaccionar ante los emergentes, las necesidades de los aprendizajes de los alumnos y las situaciones en contextos situados, entre otros factores, y de llevar y corregir "el rumbo". En cambio, las decisiones ante la presencia de los emergentes didácticos - incorporarlos o dejarlos de lado-, las capacidades para saber cuándo abandonar lo auto-prescripto, dan cuenta de la profesionalización y la autonomía docente y ayudan a reflexionar sobre el actuar en su complejidad, con la conciencia del sentido de las decisiones tomadas durante ese actuar. La reflexión en torno al actuar posibilita la toma de conciencia y la comprensión de los motivos de dichas decisiones y apunta a aprehender en mayor medida la complejidad didáctica del trabajo docente.

\section{Conclusiones}

La revisión de las categorías del trabajo docente desde el marco teórico del interaccionismo socio-discursivo y su representación en forma gráfica sistematiza la información sobre esta metodología para el análisis de las clases de Lengua y Literatura y releva un elemento hasta ahora no presentado en las relaciones entre el trabajo prescripto y el trabajo real: el trabajo concretado. Esta categoría aquí propuesta posibilitaría encontrar, en la sucesión de clases, cómo lo prescripto se articula en continuidades y negociaciones con los emergentes, revisándose en función de la transposición didáctica y de los objetivos, metas y finalidades de la enseñanza. Se revela de interés para identificar, en las entrevistas de reconfiguración del actuar donde el docente es auto-confrontado con su trabajo, aquello que conjeturó que iba a realizar y que efectivamente hizo, como un aspecto del trabajo representado.

Ante la complejidad del trabajo docente en sus múltiples niveles de prescripción y auto-prescripción, y ante las realidades diversas de la clase (el trabajo real) se requiere de elementos que nos permitan asir comprensivamente las transformaciones que modifican las prácticas otorgando sentido al actuar. 
Las categorías precedentemente organizadas y el análisis de clases con estas categorías constituyen un instrumento que busca interpelar lo realizado durante el trabajo docente para la interpretación y dotación de sentido en la tarea de enseñanza. Permiten identificar continuidades y cambios de acción entre aquello planificado y aquello que efectivamente sucede en las clases, manifestando la experiencia profesional de un docente en la toma de decisiones con respecto a concretar la tarea prevista, modificarla atendiendo a los diversos factores que se suceden en situación o dejarla de lado.

El análisis del trabajo docente conforma, pues, una síntesis metodológica que podría ser de utilidad en la formación inicial y continua de profesores de Lengua y Literatura, para tomar conciencia sobre las decisiones didácticas que se motorizan en una clase y, en definitiva, para analizar y reflexionar sobre la práctica profesional de los profesores.

\section{Referencias bibliográficas}

- Bronckart, J.P. (2004). Actividad verbal, textos y discursos. Por un interaccionismo socio-discursivo. Madrid: Infancia y Aprendizaje.

- Bronckart, J.P. (2007). Desarrollo del lenguaje y didáctica de las lenguas. Buenos Aires: Miño y Dávila.

- Bronckart, J.P. (2008). Genres de textes, types de discours et «degrés» de langue, Texto!, XIII, 1. Disponible en línea: http://www.revue-texto.net/docannexe/file/86/ bronckart_rastier.pdf

- Bronckart, J.P. (2012). En las fronteras del Interaccionismo socio-discursivo: aspectos lingüísticos, didácticos y psicológicos. En Riestra, D.; Tapia, S. M. y Goicoechea, M. V. (Comps.). Terceras Jornadas Internacionales de Investigación y Prácticas en Didáctica de las lenguas y las literaturas. (pp. 39- 59). Bariloche: GEISE.

- Cuesta, C. (2011). Lengua y Literatura: disciplina escolar. Hacia una metodología circunstanciada de su enseñanza. Tesis para la obtención del Doctorado en Letras. Universidad de La Plata. Disponible en línea: http://www.memoria.fahce.unlp.edu.ar/ tesis/te.641/te.641.pdf

- Faïta, D. (2002). Apport des sciences du travail à l'analyse des activités enseignantes, Skhôle, hors-série, 1, pp. 17-23.

- Goicoechea, M. V. (2015). "Nociones textuales y contenidos gramaticales en una clase de nivel superior: Análisis del trabajo docente". En Riestra, D.; Tapia, S. M. y Goicoechea, M. V. (Comps.). Cuartas Jornadas Internacionales de Investigación y Prácticas en Didáctica de las lenguas y las literaturas. (pp. 152-172). Viedma: UNRN.

- Pichon Riviére, E. (1985). El proceso grupal. Buenos Aires: Editorial Nueva Visión.

- Riestra, D. (2004). Las consignas de trabajo en el espacio socio-discursivo de la enseñanza de la lengua. Tesis de Doctorado. Ginebra: Universidad de Ginebra.

- Riestra, D. (2008). Las consignas de enseñanza de la lengua. Un análisis desde el interaccionismo socio discursivo. Buenos Aires: Miño y Dávila.

- Riestra, D. (2010a). El trabajo docente en la enseñanza de la lengua: Los textos y el análisis entre los géneros y los tipos de discurso. En V. M. Castel y L. Cubo de Severino 
Revista de la Escuela de Ciencias de la Educación, año 13, nRo. 12, vol. 2, Julio a diciembre de 2017. Páginas 87-105. ISSN 1851-6297. ISSN 2362-3349 (EN LINEA). ANÁLISIS DEL TRABAJO DOCENTE: RELACIONES ENTRE LO PRESCRIPTO Y LO REAlizado en Clases de lengua y literatura. Stella Maris Tapia

(Eds.). La renovación de la palabra en el bicentenario de la Argentina. Los colores de la mirada lingüística (pp. 1129-1138). Mendoza: FFyH, UNCuyo.

- Riestra, D. (2010b). Para debatir: ¿Cómo surgen y cómo llegan las propuestas didácticas? El toldo de Astier. Propuestas y estudios sobre la enseñanza de la lengua y la literatura, 1, 1. Disponible en línea: www.eltoldodeastier.fahce.unlp.edu.ar

- Schwartz, Y. (2002). Quelles sont les évolutions du champ de la prescription, 37 Congrès de la self Aix, Provence, septembre 2002. Consultado el 15 de enero de 2016. Disponible en línea : http://sites.univ-provence.fr/ergolog/Bibliotheque/Schwartz/ Quelles\%20sont\%20les\%20\%E9volutions\%20du \%20champ $\% 20$ de $\% 201 a \% 20$ prescription.pdf

- Souto, M. (1996). La clase escolar. Una mirada desde la didáctica de lo grupal. En Camilloni, A. ; Davini, M. C. ; Edelsein, G. et al. Corrientes didácticas contemporáneas. (pp. 117-155). Buenos Aires: Paidós.

- Tapia, S. M. y Goicoechea, M. V. (2012). Discusiones de los docentes de lengua acerca de su propio trabajo. Revista de la Escuela de Ciencias de la Educación, 7, 8, pp. 291-307.

- $\quad$ Tapia, S. M. y Riestra, D. (2014). El momento de la reflexión sobre la lengua en el aula: ¿explicación gramatical azarosa o sistematización de contenidos específicos? Saga, Revista de Letras. Universidad Nacional de Rosario, 1, 1, pp. 178- 206. Disponible en línea: http://sagarevistadeletras.com.ar/numero/primer-semestre-2014/

- Tapia, S. M. (2016). El análisis del trabajo docente como metodología de análisis de las prácticas. Comunicación presentada en $V$ Jornadas Internacionales de Investigación y Prácticas en Didáctica de las Lenguas y las Literaturas, UNRN. Bariloche, 3 y 4 de noviembre de 2016.

- Schneuwly, B. (2000). Les outils de l'ensegnant. Un essai didactique. Repères, 22, pp. 19-38.

- Yvon, F.; Clot, Y. (2004). Apprentissage et développement dans I'analyse du travail enseignant. Psicology da Education, Sao Paulo, 19, 2, pp. 11-38.

\section{Fuentes documentales}

- Consejo Federal de Educación. (2009). Lineamientos políticos y estratégicos de la Educación Secundaria Obligatoria. Anexo a la Resolución 84/09. Consultado el 15 de enero de 2016. Disponible en línea: http://www.me.gov.ar/consejo/resoluciones/ res09/84-09.pdf

- Ministerio de Educación. Consejo Federal de Educación. Presidencia de la Nación. (2011). Núcleos de Aprendizajes Prioritarios (NAP). Ciclo Básico. Educación Secundaria. Lengua y Literatura. Consultado el 15 de enero de 2016. Disponible en línea: http://www.educ.ar/recursos/ver?rec_id=110569

- Ministerio de Educación. Consejo Federal de Educación. Presidencia de la Nación. (2012). Núcleos de Aprendizajes Prioritarios (NAP). Campo de Formación General. Ciclo Orientado. Educación Secundaria. Lengua y Literatura. Consultado el 15 de enero de 2016. Disponible en línea: http://www.me.gov.ar/consejo/resoluciones/ res12/180-12_06.pdf 